\title{
Citações de Fontes Externas nas \\ Melhores Redaç̃es da Fuvest (1999-2013)
}

\author{
Quotations of External Sources in the Best Essays of Fuvest
}

(1999-2013)

Rodrigo Moura Lima de Aragão*

Valdir Heitor Barzotto**

Resumo: Este artigo apresenta resultados da análise de 722 redações consideradas como melhores pela Fundação Universitária para o Vestibular (Fuvest) da Universidade de São Paulo nos vestibulares dos anos 1999 a 2013 quanto ao uso de citações de fontes não pertencentes às propostas de redação dos processos seletivos. Foram objetivos do exame realizado: descrever a incidência de textos com citações de fontes externas, identificar os autores externos mais citados, retratar o percurso do número de autores externos citados nas redações. Como resultado da análise, observaram-se citações de fontes externas em textos de todos os vestibulares ponderados e constatou-se um aumento no uso desse recurso: no vestibular de 1999, 13,7\% dos textos continham citações de fontes externas; no de 2013, esse número saltou para 92,6\%. Verificou-se, além disso, que a trajetória de autores citados ao longo dos vestibulares e o conjunto do corpus mostram a preferência dos candidatos por pensadores estrangeiros como Aristóteles. Ademais, observaram-se em todos os vestibulares tanto textos sem a presença de autores externos como textos com grandes números desses autores citados,

\footnotetext{
* Mestre em Filologia e Língua Portuguesa pela Universidade de São Paulo (2012). Professor da Faculdade de Tecnologia de Itaquera "Prof. Miguel Reale". Contato: aragao_rodrigo@yahoo.com.br.

** Livre-docente na área de Metodologia do Ensino de Língua Portuguesa. Doutor em Linguística pela Universidade Estadual de Campinas (1998). Professor Associado da Faculdade de Educação da Universidade de São Paulo. Contato: barzotto@usp.br.
} 
constatou-se um aumento na média de autores externos citados por redação e verificou-se uma mudança na moda de 0 para 1 autor externo citado por redação.

Palavras-chave: Redação de vestibular. Citação. Intertextualidade.

Abstract: This article presents findings of the analysis of 722 essays that were highly evaluated by the Fundação Universitária para o Vestibular (Fuvest) of the University of São Paulo in the 1999-2013's entrance examinations concerning quotations from sources that did not belong to the composition exams. The objectives of the analysis were the following: to determine the rate of texts containing quotations from external sources, to identify the most quoted external authors, to describe the variations of the number of external authors quoted within the essays. As a result, quotations from external sources were observed in texts of all examinations and an increase in their use was found: in the 1999's examination $13.7 \%$ of the texts had external quotations; in the 2013's examination this number leapt to $92.6 \%$. Furthermore, it was observed that the changes related to the quoted authors and the whole corpus show the preference of the applicants for foreign thinkers. Also, texts without external authors as well as texts with many of these authors were observed in all examinations, an increase in the average of external authors quoted by essay was noted, and a change in the mode from 0 to 1 external author quoted by essay was found.

Keywords: University entrance examination essay. Quotation. Intertextuality.

\section{Introdução}

O estudo de citações consolidou-se como via para a descrição de aspectos variados da produção científica de diferentes ramos do saber. Mediante o exame de referências presentes em textos científicos, é possível verificar, entre outros elementos, quais autores, artigos, periódicos e livros são mais (e menos) citados e, com isso, compor retratos das constelações de poder em que se desenvolvem vertentes do conhecimento. Exemplos de 
trabalhos que fluem nesse sentido em diferentes áreas são os estudos de marketing de Vieira (2003), de psicologia de Sampaio (2008), de empreendedorismo de Borba, Hoeltgebaum e Silveira (2011) e de medicina de Lustosa et al. (2012).

Apesar de sua afirmação enquanto objeto de investigação próprio ao domínio científico, as citações evidentemente ultrapassam tal âmbito, sendo comuns a textos jornalísticos, religiosos, políticos, filosóficos.

Além desses ambientes textuais em que a citação parece estar em seu lugar natural, pode-se notar que esse recurso não é raro em redações feitas por participantes de processos seletivos de instituições de ensino superior textos situados em um contexto de transição pré-acadêmico ou (quase) pós-escolar. Nesse tipo de texto, cujo propósito não é fazer ciência (não se enquadrando, portanto, entre os científicos), é provavelmente mais corriqueira a citação de excertos constantes nos fragmentos das chamadas coletâneas, tanto porque algumas propostas de redação estimulam ou demandam de maneira direta a prática da citação, quanto porque o fato de que uma proposta solicite a consideração da coletânea apresentada já é suficiente para que o candidato entenda que deve dar provas de que ponderou e compreendeu os excertos oferecidos, o que é feito por meio da citação. Entretanto, notam-se ainda citações de fontes externas.

Esse tipo de citação, de bibliografia mais ampla que a constante na coletânea, é explorado apenas timidamente nos trabalhos precedentes sobre redações de vestibular. Quando há menção a citações de material estranho (ou aparentemente estranho) às coletâneas, o tópico é abordado por meio de aportes teóricos como, entre outros, os que lidam com intertextualidade (MARQUES, 1997; CATELLAN; BOTTEGA, 2003) ou dialogismo (CASTALDO, 2009), não recebendo a atenção que lhe é dispensada nas investigações referentes a textos científicos. Seria possível indagar se o exame de redações de Rocco (1981), em que aparecem autores como Carlos Drummond de Andrade, Luís Vaz de Camões e o presidente americano Jimmy Carter, já não seria uma análise aprofundada do objeto. Entretanto, embora a autora use o termo "citação", as ocorrências presentes em seu corpus parecem restritas à menção de nomes de autores, exceto por um caso, em que há a aproximação de um conteúdo exposto ao que supostamente um autor teria divulgado (ocorrência com Jimmy Carter). A 
escassez de análises a respeito dessas fontes citadas em redações de vestibular consiste em uma das principais motivações deste trabalho.

Ora, mas haveria sentido em tratar o assunto com tal diligência se os textos em questão são pré-acadêmicos, e não acadêmicos ou científicos? Responde-se a essa pergunta com dois excertos e nova indagação:

Por isso é que, contraditoriamente, ao mesmo tempo em que o capitalismo promove o aumento exponencial da riqueza social, torna o indivíduo mais pobre ao alienar reiteradamente a capacidade humana de produção de suas necessidades, coisificando-as. Analisando o empobrecimento das necessidades e capacidades humanas sob o capital, Heller aponta dois processos que lhe são intrínsecos: a 'redução' e a 'homogeneização', os quais incidem sobre todas as classes sociais, embora de maneira desigual. [...]

Este panorama, porém, não é exclusivo da sociedade contemporânea. Karl Marx, filósofo e economista alemão, preconizava já no Século XIX que o capitalismo começava a apresentar sinais de superprodução e de saturação de mercados. Para evitá-los, as grandes corporações fariam uso da mídia para veicular a ideologia do consumo, de modo que estes valores fossem introjetados pela população. Obteve-se êxito nesta investida, acarretando na sociedade o quadro de, nos termos de Marx, 'fetichização das mercadorias', no qual o simbolismo por trás da compra carregaria enorme prestígio social. Zygmunt Bauman, sociólogo polonês, a partir da obra marxista e do cenário moderno, atesta o perigo desta situação tão presente até hoje: o mercado se empodera cada vez mais, em detrimento das relações humanas, as quais fragilizam-se exponencialmente. [...]

Qual dos fragmentos acima não é acadêmico (científico)? O primeiro pertence à segunda seção do ensaio intitulado 'Consumo consciente': O ecocapitalismo como ideologia, de Silva, Araújo e Santos (2012), que foi publicado na revista Katálysis, periódico que integra a coleção da Scientific Electronic Library Online. O excerto foi transcrito exatamente como consta no original, exceto pela supressão do ano de publicação e do número da página do texto de Heller 
“(1986, p. 65)", que seriam pistas claras de que se trata de um texto acadêmico. Já o segundo fragmento pertence a uma redação produzida no processo seletivo realizado pela Fundação Universitária para o Vestibular (Fuvest) da Universidade de São Paulo em 2012-2013, de autoria não divulgada pela fundação. Suas citações não provêm da proposta distribuída aos participantes da seleção.

Diante de casos como esse, em que se verifica incorporação de ideias e frases de outros autores similar àquela de trabalhos acadêmicos e científicos, parece oportuno e necessário um exame de citações de fontes externas em redações de vestibular, a fim de que se possa avançar na compreensão de tais textos e de seu entorno. Trata-se de recurso comum a redações bem avaliadas? Quem seriam os teóricos ou as personalidades mais citadas em textos bem-sucedidos? Quantos autores estranhos às coletâneas seriam citados em provas de composição escrita de bom desempenho? O que o estudo das citações pode indiciar sobre a concepção de texto que está se delineando no ensino superior?

Este trabalho apresenta respostas para questões como essas a partir da análise de uma amostra das redações consideradas como melhores pela Fuvest nos vestibulares pertinentes ao ingresso em cursos superiores nos anos 1999 a 2013. Foram objetivos principais do processo investigativo do qual este artigo é produto: primeiro, descrever a incidência de redações com citações de fontes externas entre textos bem avaliados nos referidos processos seletivos; segundo, descobrir quais autores alheios às coletâneas são mais citados nos textos de êxito; terceiro, retratar a trajetória do número de autores externos citados nas avaliações escritas bem-sucedidas.

\section{Citação: concepção e pressupostos}

No que diz respeito ao estabelecimento de parâmetros e normas para a comunicação científica no Brasil, o principal organismo é a Associação Brasileira de Normas Técnicas (ABNT). Segundo esse organismo, citação é a "Menção de uma informação extraída de outra fonte" (ABNT, 2002, p. 1) e pode ser de dois tipos: citação direta, que é a "Transcrição textual de parte da obra do autor consultado", e citação indireta, que corresponde ao "Texto baseado na obra do autor consultado" (ABNT, 2002, p. 2). 
Essa conceituação não se alinha exatamente à literatura internacional sobre o tema, uma vez que, diferentemente do que se encontra em textos estrangeiros, parece enquadrar a paráfrase e o resumo (tipos de textos que se baseiam em outros textos) como uma forma de citação. A American Psychological Association (2009, p. 170-174), por exemplo, faz distinção entre a transcrição de outros textos ("quotation"), a paráfrase ("paraphrasing") e a indicação do autor e da fonte do excerto transcrito ou parafraseado (“citation”). Hamada, Hirao e Yui (1997, p. 9-12) distinguem a transcrição de fragmentos de outras fontes ("in’yô") da síntese do conteúdo de outras obras ("yôyaku”).

Constata-se, entretanto, semelhança entre a definição da ABNT e interpretações encontradas em livros brasileiros que abordam o assunto (SEVERINO, 2002; MARCONI; LAKATOS, 2005; RODRIGUES, 2009), o que sugere certo consenso quanto ao termo. Neste estudo, assume-se citação de forma também abrangente, isto é, incluindo a paráfrase e a síntese, pois, apesar das diferenças entre parafrasear, resumir e transcrever, considera-se a essência de suas operações uma só: inclui-se em certo texto algo de outro texto.

De maneira mais específica, assume-se citação como a transcrição, a paráfrase, o resumo ou a menção de parte do conteúdo de outra obra, seja ela de autoria do mesmo autor do texto citante ou não. Ainda, entende-se que sejam necessários dois elementos para a existência de citações: primeiro, o conteúdo citado; segundo, a indicação do autor e/ou da obra citada. Embora no caso de textos acadêmicos e científicos tanto a indicação do autor quanto a da obra sejam mandatórias, neste trabalho considerou-se que, ao haver a explicitação de um elemento, remete-se ao outro por metonímia em uma redação.

\section{Estratégias de Pesquisa}

O corpus deste estudo foi composto pelas redações disponibilizadas pela Fuvest (2013) em seu site como "algumas das melhores redações". Trata-se de 722 textos produzidos por candidatos a vagas de cursos de graduação da Universidade de São Paulo e da Faculdade de Ciências Médicas da Santa Casa nos vestibulares dos anos 1999 a 2013 (Tabela 1). 


\begin{tabular}{|c|c|c|}
\hline \multirow{2}{*}{ Vestibular } & \multicolumn{2}{|c|}{ Redações } \\
\hline & $\mathrm{n}$ & $\%$ \\
\hline 1999 & 51 & 7,1 \\
\hline 2000 & 57 & 7,9 \\
\hline 2001 & 63 & 8,7 \\
\hline 2002 & 114 & 15,8 \\
\hline 2003 & 48 & 6,7 \\
\hline 2004 & 51 & 7,1 \\
\hline 2005 & 29 & 4,0 \\
\hline 2006 & 15 & 2,1 \\
\hline 2007 & 50 & 6,9 \\
\hline 2008 & 35 & 4,9 \\
\hline 2009 & 44 & 6,1 \\
\hline 2010 & 53 & 7,4 \\
\hline 2011 & 56 & 7,8 \\
\hline 2012 & 28 & 3,9 \\
\hline 2013 & 27 & 3,7 \\
\hline Total & 722 & 100,0 \\
\hline
\end{tabular}

Nota: Percentuais arredondados.

O exame realizado deteve-se essencialmente em três aspectos dos textos. Primeiro, verificou-se a presença de citações de material estranho às coletâneas que fazem parte das propostas de redação. Segundo, registraram-se os autores de fontes externas citados nos textos. Por último, anotaram-se os números de autores de fontes externas identificados. Além disso, coletaram-se exemplos de citações das redações a fim de ilustrar o que os números e os autores indicam.

Por se tratar de corpus extenso, realizou-se primeiro uma análise preliminar de parte do material (textos produzidos nos vestibulares de 1999, 2000, 2012 e 2013), a fim de estabelecer critérios que permitissem conduzir o exame com menor oscilação interpretativa. Esses critérios estão reunidos a seguir e dizem respeito, basicamente, ao tipo de ocorrência que foi considerado citação (de fonte externa) a partir da concepção exposta na seção precedente':

${ }^{1}$ A partir daqui, os exemplos das redações são acompanhados da indicação de sua fonte por meio da letra "R", de "redação", mais o número do texto de origem segundo a numeração do site da Fuvest e do ano do vestibular correspondente. Por exemplo: "(R11, 2013)", após o primeiro exemplo, indica que o excerto é parte da redação de número 11 do vestibular da Fuvest para ingresso nos cursos de graduação no ano de 2013. 
a) A inclusão de certo conteúdo com a menção de seu autor e obra foi considerada citação.

Exemplo:

"Claro exemplo disso é a personagem Jacinto de Tormes, do livro 'A Cidade e as Serras', de Eça de Queirós, que, enquanto vive em Paris, possui uma extensa livraria e todos os instrumentos tecnológicos imagináveis.” (R11, 2013)

b) A inclusão de certo conteúdo sem outra marca que não a menção de seu autor foi considerada citação.

Exemplo:

"F. Kafka não poderia ser mais contemporâneo: o homem está literalmente tornando-se um repugnante inseto, alienado do contexto histórico-político ao qual está inserido e preocupado de maneira assustadora com o trabalho, com o lucro e com quantas horas de compras consegue arcar.” (R7, 2013)

c) A inclusão de certo conteúdo sem outra marca que não a menção de sua obra foi considerada citação, sendo essa citação atribuída ao(s) autor(es) da obra.

Exemplo:

“Tyler Durden, concretização de uma série de desejos secretos e de frustrações do personagem principal de 'O Clube da Luta', abre uma discussão acerca do ser e do sentir numa era em que o consumo é imperativo. O filme, baseado no livro homônimo, levantou polêmicas [...]" (R16, 2013)2

d) A inclusão de conteúdo que, embora seja de autor presente na coletânea, difere da transcrição da coletânea foi considerada citação externa.

Exemplo:

““O homem é um ser político', já dizia Aristóteles.” (R16, 2012)3

${ }^{2}$ Interpreta-se que são citados filme e livro na passagem. A citação do filme foi atribuída ao diretor David Fincher; a do livro, ao autor Chuck Palahniuk.

${ }^{3}$ O trecho presente na coletânea da prova de 2012 é o seguinte: "A ciência mais imperativa epredominante sobre tudo é a ciência política, pois esta determina quais são as demais ciências que devem ser estudadas na pólis. Nessa medida, a ciência política inclui a finalidade das demais, $e$, então, essa finalidade deve ser o bem do homem. Aristóteles. Adaptado." (FUVEST, 2013). 
e) A inclusão de termo ou expressão qualificada por palavras como "marxista", quando estas puderam ser interpretadas como "de Marx" ("de X"), foi considerada citação.

Exemplos:

"Ideologia, no seu sentido marxista, é uma ideia que tem como objetivo ofuscar a visão da realidade.” (R1, 2013)

"Dessa maneira, conclui-se que o consumismo é o oposto do 'imperativo social' kantiano, posto que de acordo com os valores daquele, o ser humano pode abdicar de sua moral ('morus'), prejudicando aos outros, para ser 'feliz'." (R25, 2013)

f) A menção de certo autor ou obra sem referência a conteúdo não foi assumida como citação.

Exemplo:

"Temos que deixar de ser a geração que diz que Marcel Proust é um parente de um piloto de F-1, que acha Titanic uma obra-prima e Picasso, um boçal. Temos, enfim, que adquirir o senso do que somos enquanto parte da humanidade." (R11, 1999)

g) A inclusão de certo conteúdo proveniente de outro texto sem menção a seu autor ou fonte não foi assumida como citação.

Exemplos:

"Deitados em berço esplêndido nascemos. Somos a elite, a nata da sociedade pega somente por uma colherzinha de café." (R33, 1999)

“A ‘última flor do Lácio’ deve ser protegida não com excessos de nacionalismo, e sim com a vontade do povo - que terá orgulho de falar Português e de ser Brasileiro.” (R54, 2000)

"Macabéas que datilografam por conveniência, macunaímas com preguiça, Brás Cubas os quais nunca trabalham ou a humanidade em geral: só querem 'vagabundear' ou serem Michelangelos; extremos nos quais o simples trabalho não tem moradia fixa.” (R9, 2006) 
b) Passagens com aparência de citação, mas cujo conteúdo nãopode ser atribuido a autor específico e obra certa, não foram interpretadas como citação.

Exemplos:

"A Igreja diz: 'O vício e o luxo são capazes de arruinar uma vida."” (R5, 2013)

“Assim caímos na triste máxima de 'você é aquilo que tem', aquilo que compra, aquilo que consome.” (R8, 2013)

“... o governo buscou o apoio popular através de anúncios e slogans, como o 'Brasil, grande potência', manipulando [...]” (R10, 2013)

"No mito das sereias, o irresistível canto dessas criaturas atrai os marinheiros em direção aos rochedos que circundam a ilha em que elas estão entrincheiradas, inevitavelmente sendo o naufrágio das embarcações o desfecho.” (R27, 2013)

"Sabe que a propaganda de margarina, com a família feliz e seu cão, não passa de um estereótipo. É crítica da propaganda eleitoral, 'margarina política' da qual sabe descrer.' (R19, 1999)

Estabelecidos esses critérios, procedeu-se à revisão do produto das análises iniciais e passou-se à análise dos textos elaborados em atendimento às propostas dos exames vestibulares dos demais anos.

É importante esclarecer que, embora o produto deste trabalho tenha alguma semelhança com o de estudos de citações a partir de referências, tais como os de Vieira (2003) e de Sampaio (2008), o percurso investigativo foi fundamentalmente outro. No levantamento realizado, os autores citados nas redações disponibilizadas no site da Fuvest, bem como as citações nelas contidas, tiveram de ser garimpados nas redações conforme os critérios apresentados. Foi necessário fazer uma busca partindo geralmente de pistas não muito precisas, ou seja, não foi possível contar com as indicações habituais que estão presentes em artigos científicos, tais como o conjunto sobrenome do autor ou autores, ano de publicação e número de página, além das referências bibliográficas. Enquanto estudos feitos sobre citações em trabalhos 
científicos contam com a explicitação desses elementos obrigatórios para as citações segundo regras da ABNT ou de outros organismos que estabelecem normas para a comunicação científica, não se pôde contar com eles no percurso de pesquisa do qual este artigo provém.

\section{Resultados}

Identificaram-se citações de fontes externas em redações de todos os vestibulares considerados. A Figura 1 reúne os percentuais de textos com citações externas nos diferentes vestibulares e aponta um aumento no uso desse recurso nas redações dos candidatos.

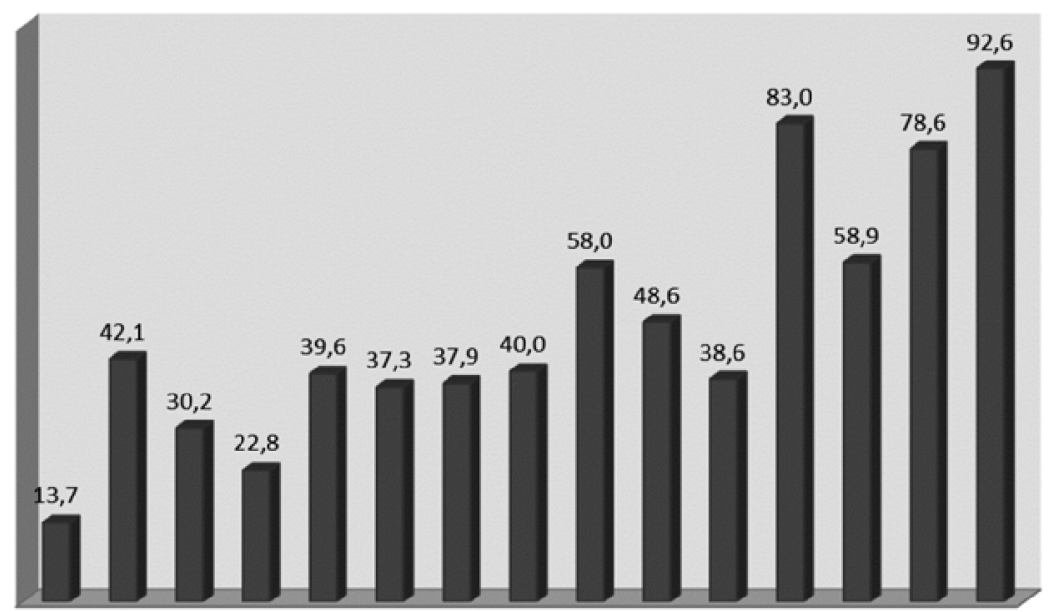

199920002001200220032004200520062007200820092010201120122013

Figura 1 - Percentual de redações com citações de fontes externas nos vestibulares.

No que diz respeito aos autores de fontes externas citados pelos candidatos, optou-se pelo registro dos mais recorrentes em cada um dos vestibulares (Figura 2) e em todos os vestibulares (Figura 3). O primeiro registro evidencia uma trajetória heterogênea que culmina no domínio de pensadores estrangeiros. O segundo, que tem Karl Marx, Zygmunt Bauman e Aristóteles nas posições iniciais, explicita esse domínio no corpus como um todo. 


\begin{tabular}{|c|c|}
\hline 1999 & $1^{\circ}$ - Joạuim Maria Machado de Assis e Luís Vaz de Camões (2 rédaçóes) \\
\hline 2000 & 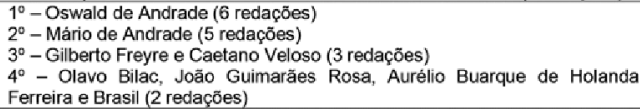 \\
\hline 2001 & $1^{\circ}$ - Karl Marx (3 redaçöes) \\
\hline 2002 & $\begin{array}{l}1^{0} \text { - Paulo Freire, Jean-Paul Sartre, Jean Piaget, Fernando Henrique } \\
\text { Cardoso, Renato Russo, João Guimaräes Rosa ( } 2 \text { redações) }\end{array}$ \\
\hline 2000 & $1^{\circ}$ - Mário de Andrade, Ary Barroso, Clarice Lispector ( 2 redaçōes) \\
\hline 2004 & $\begin{array}{l}1^{\circ} \text { - Karl Marx ( } 3 \text { redaçōes) } \\
2^{\circ}-\text { Santo Agostinho e Georg Hegel (2 redações) }\end{array}$ \\
\hline 2005 & $1^{\circ}-$ Sigmund Freud ( 2 redações) \\
\hline 2006 & Sem autores citadós em dois ou mais textos. \\
\hline 2007 & $\begin{array}{l}1^{\circ}-\text { Aristóteles ( } 3 \text { redações) } \\
2^{\circ}-\text { Vinicius de Moraes e Thomas Hobbes ( } 2 \text { redações) }\end{array}$ \\
\hline 2008 & $\begin{array}{l}1^{\circ} \text { - José Maria de Eça de Queirós, Carlos Drummond, Wikipédia ( } 2 \\
\text { redaçöes) }\end{array}$ \\
\hline 2009 & $\begin{array}{l}1^{\circ}-\text { Albert Einstein ( } 3 \text { redaçöes) } \\
2^{\circ}-\text { Isaac Newton, Galileu Galilei, Graciliano Ramos, Carlos Drummond de } \\
\text { Andrade, João Guimarães Rosa, Michel Foucault, Ludwig van Beethoven, } \\
\text { John Lennon ( } 2 \text { redações) }\end{array}$ \\
\hline 2010 & $\begin{array}{l}1^{\circ}-\text { Platão (8 redaçóes) } \\
2^{\circ}-\text { René Magritte (5 redações) } \\
3^{\circ}-\text { Friedrich Nietzche e Guy Debord ( } 4 \text { redações) } \\
4^{\circ}-\text { Joaquim Maria Machado de Assis, Carl Jung e Sigmund Freud ( } 3 \\
\text { redaçốes) } \\
5^{\circ}-\text { Aristóteles, Ferdinand de Saussure, Ingmar Bergman, Pedro Américo, } \\
\text { Michel Foucault, Jean-Paul Sartre, Jean Baudrillard, Theodor Adorno (2 } \\
\text { redaçőes) }\end{array}$ \\
\hline 2011 & $\begin{array}{l}1^{\circ} \text { - Zygmunt Bauman ( } 6 \text { redaçöes) } \\
2^{\circ} \text { - Karl Marx ( } 5 \text { redaçóes) } \\
3^{\circ} \text { - Aristóteles ( } 4 \text { redações) } \\
4^{\circ} \text { - Clinton Richard Dawkins, José Maria de Eça de Queirós, Renato Russo, } \\
\text { Hanna Arendt, Joaquim Maria Machado de Assis, Thomas Hobbes (2 } \\
\text { redaçö́es cada) }\end{array}$ \\
\hline 2012 & $\begin{array}{l}1^{\circ}-\text { Zygmunt Bauman (5 redaçōes) } \\
2^{\circ}-\text { Bertolt Brecht e Aristóteles(4 redações) } \\
3^{\circ}-\text { Jean-Jacques Rousseau (3 redaçôes) } \\
4^{\circ}-\text { Gilles Lipovetsky e Platão (2 redaçōes) }\end{array}$ \\
\hline 2013 & $\begin{array}{l}1^{\circ} \text { - Karl Marx (8 redações) } \\
2^{\circ}-\text { Zygmunt Bauman ( } 7 \text { redaçöes) } \\
3^{\circ}-\text { Aloísio de Azevedo ( } 3 \text { redaçóes) } \\
4^{\circ}-\text { José Maria de Eça de Queirós, Gilles Lipovetsky e Michel Foucault (2 } \\
\text { redaçōes) }\end{array}$ \\
\hline
\end{tabular}

Figura 2 - Autores mais citados nas melhores redações dos vestibulares da Fuvest.

\begin{tabular}{|c|c|c|}
\hline Posição & Incidência & Autor(es) \\
\hline $1^{\circ}$ & 24 redaçö́es & Karl Marx \\
\hline $2^{a}$ & 22 redaçōes & Zygmunt Bauman \\
\hline $3^{\circ}$ & 15 redaçöes & Aristóteles \\
\hline $4^{\circ}$ & 13 redaçōes & Joaquim Maria Machado de Assis e Platão \\
\hline $5^{a}$ & 9 redaçōes & $\begin{array}{l}\text { Jean-Paul Sartre, João Guimaräes Rosa, Michel Foucault, } \\
\text { Sigmund Freud e Thomas Hobbes }\end{array}$ \\
\hline $6^{a}$ & 8 redaçōes & Friedrich Nietzche e Mário de Andrade \\
\hline $7^{\circ}$ & 7 redaçōes & $\begin{array}{l}\text { Charles Darwin, Jean-Jacques Rousseau, José Maria de Eça } \\
\text { de Queirós e Oswald de Andrade }\end{array}$ \\
\hline $8^{a}$ & 6 redações & René Magritte \\
\hline $9^{\circ}$ & 5 redaçöes & $\begin{array}{l}\text { Albert Einstein, Caetano Veloso, Carlos Drummond de } \\
\text { Andrade, Clarice Lispector, Emile Durkheim, Fernando Pessoa, } \\
\text { Georg Hegel, Gilles Lipovetsky, Graciliano Ramos, Immanuel } \\
\text { Kant, Nicolau Maquiavel, Organizaçăo das Naçôes. Unidas e } \\
\text { Theodor Adorno }\end{array}$ \\
\hline $10^{\circ}$ & 4 redaçōes & $\begin{array}{l}\text { Aluisio de Azevedo, Arthur Schopenhauer, Bertolt Brecht, Carl } \\
\text { Jung. Eric Hobsbawn, Gilberto Freyre, Guy Debord, José de } \\
\text { Alencar, Luis Vaz de Camōes, Renato Russo, Santo Agostinho } \\
\text { e Milton Santos }\end{array}$ \\
\hline
\end{tabular}

Figura 3 - Autores de fontes externas mais citadas nas melhores redações dos vestibulares da Fuvest (1999-2013). 
A título de ilustração, apresentam-se a seguir fragmentos de redações com citações dos três autores mais citados no corpus.

"Conclui-se, portanto, em uma alusão ao pensamento marxista, que razões externas causam esses ideais, em outras palavras, a conjuntura da sociedade nacional desgasta pelo capitalismo e política vacilante são os causadores das ações violentas dos grupos neofascistas." (R47, 2001)

“Karl Marx, no século XIX, já duvidava que o progresso tecnológico transformaria o tempo em um aliado do homem em sua eterna busca pela realização pessoal, e a história da civilização moderna não deixa por menos [...]” $(\mathrm{R} 8,2004)$

"A estrutura altera a superestrutura e a cada vez que mudam as classes dominantes, mudam também seus discursos e ideologias. Karl Marx elaborou essa teoria no século XIX e é incrível verificar o quão atual ela se mantém.” (R12, 2013)

"Além disso, Zigmund Bauman ressalta o fim da procrastinação, prática cultural na qual a satisfação era adiada, mediante um esforço contínuo, para um poder de consumo maior no futuro.” (R5, 2013)

"Segundo o sociólogo polonês Zygmunt Bauman, a sociedade líquida contemporânea solubiliza os laços entre as pessoas. De fato, a manutenção da relação entre dois indivíduos está sujeita à continuidade de ambos no mesmo patamar econômico.” (R27, 2013)

"Aristóteles postulou que o homem é um ser social. A necessidade humana de conviver não é invenção ou imposição civilizatória, é instintiva. Nem mesma é exclusiva da espécie humana, porquanto se manifesta em diversos outros animais [...]" (R49, 2007)

“Segundo Aristóteles, 'O homem é um animal político'. Assim, o ser humano está fadado a viver em sociedade, relacionando-se com outros." (R51, 2011) 
Quanto ao número de autores de fontes externas citados nas redações examinadas, a Tabela 2 reúne medidas-resumo referentes a esse número. Os mínimos e máximos mostram que houve textos sem a citação de autores de fontes externas em todos os vestibulares e, ainda, que algumas redações chegaram a ter seis, sete e até mais autores externos citados em seu corpo. As médias indicam um aumento no número de autores de fontes externas citados ao longo dos anos, com uma oscilação (desvio-padrão) que não se manteve constante. Os números de maior recorrência (modas) apontam que, ao passo que em 1999 a ausência de autores externos era dominante, em 2012 e em 2013 o mais comum foi que as redações bem avaliadas apresentassem a citação de um autor de fonte externa.

\begin{tabular}{|c|c|c|c|c|c|}
\hline Vestibular & Mínimo & Máximo & Média & $\begin{array}{l}\text { Desvio- } \\
\text { Padrão }\end{array}$ & Moda \\
\hline 1999 & 0 & 7 & 0,29 & 1,07 & 0 \\
\hline 2000 & 0 & 4 & 0,77 & 1,09 & 0 \\
\hline 2001 & 0 & 4 & 0,44 & 0,85 & 0 \\
\hline 2002 & 0 & 4 & 0,38 & 0,79 & 0 \\
\hline 2003 & 0 & 4 & 0,56 & 0,84 & 0 \\
\hline 2004 & 0 & 3 & 0,58 & 0,87 & 0 \\
\hline 2005 & 0 & 2 & 0,45 & 0,62 & 0 \\
\hline 2006 & 0 & 3 & 0,73 & 1,00 & 0 \\
\hline 2007 & 0 & 6 & 0,86 & 1,11 & 1 \\
\hline 2008 & 0 & 4 & 0,83 & 1,16 & 0 \\
\hline 2009 & 0 & 7 & 0,89 & 1,50 & 0 \\
\hline 2010 & 0 & 9 & 1,85 & 1,57 & 2 \\
\hline 2011 & 0 & 5 & 0,98 & 1,06 & 0 \\
\hline 2012 & 0 & 5 & 1,32 & 1,23 & 1 \\
\hline 2013 & 0 & 5 & 1,89 & 1,26 & 1 \\
\hline
\end{tabular}

Nota: Percentuais arredondados.

Por último, apresentam-se, novamente a título de ilustração, dois fragmentos de redações examinadas em que há a citação de, respectivamente, cinco e nove autores de fontes externas:

Fluidez é uma palavra que cabe bem na descrição do mundo contemporâneo. Na escalada profissional, nos relacionamentos pessoais ou em qualquer fato diário, perpetua-se o egoísmo, que leva o homem à condição de máquina. E voláteis tornam-se os vínculos com as pessoas, e mesmo com a vida, devido a esse imediatismo em benefício 
próprio. A superficialidade desse hedonismo exagerado contenta a maioria, que encarna personagens literários como o português João Romão, de 'O Cortiço' [1: Aluísio de Azevedo], os nobres amigos do fidalgo Jacinto, de 'A Cidade e as Serras' [2: Eça de Queirós] ou mesmo o ensimesmado Bento Santiago, de 'Dom Casmurro' [3: Machado de Assis]. Poucos são os que se lembram de parar e olhar ao redor.

A História nos dá grandes exemplos de figuras expoentes da abnegação, como Gandhi, Madre Teresa de Calcutá e Francisco de Assis. Está certo que estes dedicaram plenamente suas vidas em causas humanitárias e o mundo ainda está muito longe disso. Ocorre que o altruísmo pode, sim, ser praticado em patamares menos intensos, mas ainda valorosos. Ninguém precisa tomar todas as dores do mundo, como pensou a personagem Amelie Poulain do filme de Jean Pierre Jeunet [4]. Até porque, como alerta o pintor Dufayel, do mesmo filme, se alguém viver somente para ajudar os outros, quem ajudará ele próprio? Amelie, então, consegue equilibrar esses anseios, deixando clara a ideia de que o caminho do meio, o meio-termo de Aristóteles [5], ainda pode ser alcançado nos dias de hoje: nem o padecimento de si próprio e a omissão do "eu" em favor somente dos outros, nem o egoísmo e a supervalorização do "eu”, mas o altruísmo, que nos faz atuantes no mundo de uma maneira saudável, levando-nos todos ao 'bem comum' do pensamento aristotélico. (R13, 2011)

Da matriz platônica [1: Platão], onde o real transcende o mundo e aristotélica [2: Aristóteles], na qual os sentidos são mediadores dessa realidade, até a fenomenologia de Heidegger [3], Sartre [4], Merleau-Ponty [5] e o estruturalismo de Lacan [6], para quem o real é desejo atravessado pelo simbólico, qualquer resposta sobre o mundo dos símbolos seria insuficiente, dada a complexidade do tema e o grande número de escolas filosóficas e da psicanálise que se alternaram historicamente pela hegemonia do conceito, como diria Gramsci [7]. Considerando esses pressupostos, talvez as palavras de Santo Agostinho [8] possam apontar um caminho. Dizia ele: 'In interiori homini habitats veritas'. Ora, se a verdade está no próprio homem, 
quem sabe não esteja faltando algo ao estruturalismo de Saussure [9], capaz de resistir ao excesso de significado e ao ceticismo da Escola de Frankfurt [...] (R13, 2010).

\section{Discussão}

Os resultados obtidos na análise realizada indicam um aumento no percentual de redações com citações de fontes externas entre os textos mais bem avaliados na trajetória dos exames vestibulares da Fuvest de 1999 a 2013. Indicam, além disso, que entre os autores citados pelos candidatos há preferência por autores estrangeiros, que poderiam ser classificados como acadêmico-filosóficos, de aceitação que extrapola suas áreas de origem. Entre os autores brasileiros citados nas redações examinadas predominam os de literatura, que muitas vezes figuram nas próprias listas de livros de leitura requerida pela Fuvest, além de alguns músicos. Ademais, os resultados apontam a presença de textos bem-sucedidos tanto sem citações de fontes externas como com altos números de citações externas em todos os vestibulares, um aumento na média de autores de fontes externas citados por redação ao longo dos anos e uma mudança no conjunto de vestibulares analisado quanto à moda, de 0 para 1 autor externo citado.

Considerando-se a ascensão das citações de fontes externas, o aumento da média do número de autores de fontes externas citados e o predomínio de autores estrangeiros como Karl Marx e Zygmunt Bauman, aparentemente as redações passaram a incorporar máscaras científicas. Se em um baile de máscaras entram apenas os mascarados, o ingresso na universidade não estaria se tornando (razoavelmente) restrito àqueles que colocam máscara de cientificidade em seus textos? É como se se buscasse não um aluno em condições de empreender a busca de uma elaboração própria, fazendo valer o princípio de que a universidade é um lugar de produção de conhecimento, e sim de entrar nesse meio mais pelo domínio de uma técnica de composição do que pela elaboração de uma reflexão. Cabe perguntar em que medida a apresentação de um aparente domínio de leitura, da natureza presente no corpus, permite inferir ou mesmo apostar que o candidato se dedicará a estudos mais pontuais e aprofundados que permitam construir uma trajetória diferenciada, menos massificada. 
O fragmento de redação exposto anteriormente no final da seção de resultados lembra, pelo excesso de citações, um texto acadêmico tal como os que têm sido aprovados por referees para figurar em periódicos científicos classificados nos mais altos patamares de avaliação. Apresenta-se, a seguir, um excerto de um artigo do periódico Cadernos de Saúde Pública, que integra a coleção da Scientific Electronic Library Online, para ilustrar essa afirmação:

Nas últimas décadas, o rápido crescimento da população idosa brasileira veio acompanhado por significativo aumento da prevalência de doenças cronicodegenerativas e de incapacidade funcional, geradores de demanda por todos os níveis dos serviços de saúde e de elevado ônus social ${ }^{1,2,3}$. Doenças crônicas e incapacitantes, de alta prevalência na população idosa, aliadas ao modelo de atenção em curso, ainda fortemente centrado no hospital, favorecem o atendimento da pessoa idosa em serviços de urgência/emergência ou durante a internação no hospital, em detrimento da atenção ambulatorial. A estratégia pública de saúde, no entanto, tem favorecido o acesso à atenção ambulatorial dos idosos, com consequente redução das hospitalizações ${ }^{4}$. Estratégia de especial importância se considerada a significativa diminuição da capacidade funcional e da qualidade de vida subsequente às internações nessa população ${ }^{5}$.

Programas de atenção domiciliar se apresentam como alternativas de atenção à saúde do idoso frágil ${ }^{6}$. Amplamente utilizados em países desenvolvidos, passaram a expandir sua atuação no Brasil somente a partir da última década do século XX, tanto no setor público, quanto no privado ${ }^{7}$. Entretanto, sua efetividade ainda não foi adequadamente avaliada em nosso país, especialmente no que se refere à população idosa. $[. .$.

\section{Referências}

1. Giacomin KC, Peixoto SV, Uchoa E, Lima-Costa MF. Estudo de base populacional dos fatores associados à incapacidade funcional entre idosos na Região Metropolitana de Belo Horizonte, Minas Gerais, Brasil. Cad Saúde Pública 2008; 24:1260-70.

2. Lima-Costa MF, Firmo JOA, Uchoa E. The Bambuí Cohort Study 
of Aging: methodology and health profile of participants at baseline. Cad Saúde Pública 2011; 27 Suppl 3:S327-35.

3. Lima-Costa MF, Veras R. Saúde pública e envelhecimento. Cad Saúde Pública 2003; 19:700-1.

4. Lima-Costa MF, Matos DL, Camargos VP, Macinko J. Tendências em dez anos das condições de saúde de idosos brasileiros: evidências da Pesquisa Nacional por Amostra de Domicílios (1998, 2003, 2008). Ciênc Saúde Coletiva 2011; 16:3689-96.

5. Siqueira AB, Cordeiro RC, Perracini MR, Ramos LR. Impacto funcional da internação hospitalar de pacientes idosos. Rev Saúde Pública 2004; 38:687-94.

6. Veras R. Em busca de uma assistência adequada à saúde do idoso: revisão da literatura e aplicação de um instrumento de detecção precoce e de previsibilidade de agravos. Cad Saúde Pública 2003; 19:705-15.

7. Silva KL, Sena RR, Terenzi C, Feuerwerker LCM, Merhy EE. Atenção domiciliar como mudança do modelo tecnoassistencial. Rev Saúde Pública 2010; 44:166-76. (BISCIONE et al., 2013, p. s74-s79)

O fragmento de redação exposto anteriormente conta com nove citações em dois parágrafos. No excerto acima, extraído de um texto acadêmico e também composto por dois parágrafos, são sete, todas indicadas por números sobrescritos que remetem às referências. Frente aos dois fragmentos, é possível sustentar a hipótese de que a máxima bastante plausível de que toda afirmação deve ser sustentada por uma citação (evidência), que é muito difundida na academia brasileira, parece estar alcançando os candidatos às vagas de cursos superiores. No entanto, ao contrário do que se espera quando se está inserido em uma cultura de produção de conhecimento, ou seja, que tais fragmentos sirvam para dar sustentação a afirmações, constatações ou proposições feitas a partir de uma pesquisa, eles têm se tornado um artifício para compor máscaras para as redações, de modo que estas se aproximem apenas formalmente do texto que cumpre a função de apresentar reflexão embasada. 
A esse respeito, é oportuno retomar o que afirmam Catellan e Bottega (2003, p. 50):

Fazer referência a um certo número de textos em relação a um tema específico parece permitir ao produtor do texto estar dizendo de si, sem o dizer explicitamente, que ele possui um conjunto de conhecimentos que lhe foi oportunizado pela leitura de um número de obras (inclusive literárias), transcendendo, inclusive, o número de excertos dados para seu uso pela equipe elaboradora da prova. Ele, portanto, leitor que é, pelo menos, nesse primeiro caso, quantitativamente, mereceria estar numa universidade. Por detrás de cada citação, poder-se-ia postular uma voz autoral que sussurra ao corretor: está vendo como sou bom leitor? Está vendo quanto eu leio? Mereço ou não mereço ser aprovado?

Trata-se de uma estratégia que, a julgar pelo fato de que as redações examinadas figuram entre as mais bem avaliadas, tem funcionado. Contudo, essa estratégia não oferece necessariamente indícios de que o candidato vá além, nem de que a universidade esteja em busca de uma passagem desse estágio de demonstração de familiaridade com certas leituras, uma vez que os textos produzidos mais à frente, de dentro da universidade, parecem apontar uma estagnação no modelo.

Além do mais, chama a atenção, conforme já apontado, o predomínio de autores estrangeiros entre os mais citados (Figura 3), autores esses cuja importância é dada como certa às vezes não só em seu domínio, mas em áreas diferentes, e que em geral são originários de países reconhecidos como produtores de conhecimento legítimo. Essa observação ganha importância quando se nota que os autores brasileiros presentes são, em sua maioria, escritores do campo literário. Apenas dois não pertencem a esse campo: Gilberto Freyre e Milton Santos, que aparecem na última colocação da listagem geral.

Assim, se o vestibular, tal como se afirma no senso comum, de fato produz indicativos sobre o que fazer no ensino médio, uma das constatações deste trabalho é a de que ele tem influenciado as escolas a familiarizar os alunos com autores sobre os quais ela mesma demonstra ter ampla aceitação, 
transformando-os em uma espécie de clichê. Os autores tornam-se clichês e os trechos extraídos de sua produção, que são em geral aqueles mais conhecidos, adquirem igualmente essa faceta.

Barzotto (2007, p. 159-160) já manifestava sua preocupação com o que percebia na produção do texto acadêmico a esse respeito:

Nas diversas áreas do conhecimento - e nos estudos da linguagem não é diferente - alguns postulados são incorporados ao discurso cotidiano dos profissionais da área, formando o que se pode chamar de seu senso comum.

Se, por um lado, é necessário que alguns termos e postulados gozem de um certo grau de consenso, até para garantir o fluxo dos diálogos entre profissionais de uma mesma especialidade, por outro lado, este mesmo consenso pode produzir uma satisfação improdutiva, fazendo cessar a interrogação.

O diálogo cotidiano entre especialistas em si não deveria ocupar o lugar da investigação ou de seus resultados, mas, uma vez aprendidos e incorporados, os termos e postulados vão ocupando espaços discursivos cada vez maiores, podendo causar a acomodação da inquietude necessária para impulsionar a pesquisa.

Quando isso ocorre na Universidade, um lugar de produção de conhecimento em que, pelo menos num nível utópico, deve-se manter o compromisso com a busca de algo novo para se dizer, uma acomodação desta natureza parece ser merecedora de enfrentamento.

Percebe-se que a conduta escrita de dedicação à repetição de autores e excertos, que constituem um senso comum supra-área, tornou-se induzida e validada em um momento anterior à produção universitária de textos acadêmicos e científicos. Já no ensino médio os alunos parecem estar sendo convidados a adentrar em e a se apossar de fragmentos de trabalhos de autores consagrados.

Uma das preocupações que a prática da citação suscita é a dificuldade na avaliação das redações, que pode ser suposta quando se consideram quem atua como corretor. Geralmente recrutados na área de letras, de titulação 
diversa, torna-se difícil admitir que qualquer corretor estará preparado para avaliar o conteúdo de uma redação como aquela da qual os parágrafos seguintes foram extraídos:

No século XVIII o filósofo prussiano Immanuel Kant iniciou na pequenina cidade de Königsberg uma das tarefas mais hercúleas da ciência ocidental - a composição de uma nova epistemologia, de um tratado capaz de proceder à análise dos meandros mais recônditos da cognoscibilidade humana. A este tratado, Kant ofereceu um título singelo - e sintomático "Crítica da Razão Pura". Dentre outros assuntos, a obra kantiana debruçou-se sobre uma espécie de "taxonomia filosófica", procurando, rigorosamente (como convém à tradição alemã) identificar todas as fronteiras dos momentos e dos processos da razão. Com efeito, Kant logrou esmiuçar um mecanismo deveras exaustivo, que contemplaria o desvelamento da complexa e mistinérvea arquitetônica do conhecimento humano. Além de descobrir fronteiras "precisas" entre as diversas faculdades da razão, Kant também propôs uma diáclase ainda mais fundamental, ao argumentar que todas as coisas que percebemos - todos os entes que contemplamos e experimentamos - não são, em verdade, as próprias causas. São apenas fenômenos: impressões balançantes, opacas e fugidias das coisas verdadeiras, a que chamou de "coisas-em-si". Assim, o filósofo procurou estabelecer uma das mais poderosas fronteiras da existência; a fronteira que medeia o mundo real, o mundo-em-si e o mundo em que vivemos, reflexo fenomenológico de uma especularidade evanescente.

O que Kant não percebeu, todavia, é que nem todas as fronteiras são nítidas. Se a ciência não pode prescindir dos expedientes poderosos da generalização e da categorização [...] (R41, 2009).

Frente a uma redação como essa, muito provavelmente a avaliação quanto à forma e à demonstração de pertencimento a um grupo de leitores de obras de ampla aceitação prevalece sobre a do conteúdo. Não se trata de desmerecer a qualidade dos corretores, mas de ter claro que, para saber se está correto o que o candidato está afirmando, é necessário ter lido trabalhos 
de Kant (e, se possível, um bom crítico à sua obra), o que não é óbvio que todo corretor tenha feito ${ }^{4} \mathrm{Na}$ verdade, parece fundamental refletir sobre a posse do repertório necessário para examinar redações com citações de autores externos como Kant, Friedrich Nietzche, Arthur Schopenhauer e Jean-Paul Sartre por parte dos corretores de vestibulares. Ainda, deve-se levar em consideração o próprio contexto de avaliação das redações, uma vez que o tempo disponível geralmente não permite recorrer às obras que auxiliariam na verificação da acuidade das exposições presentes nos textos.

\section{Considerações Finais}

A redação de vestibular de êxito, tal como vista na análise realizada, aparentemente está assumindo a configuração de imitação dos textos acadêmicos e científicos contemporâneos. Trata-se de produção mascarada, em que autores, obras, frases e ideias consagradas tornam-se clichê. Maravilhar-se ou contentar-se com isso é o bastante para cumprir o papel formativo e selecionador da avaliação dos vestibulares?

Acredita-se que não. Tão somente tem-se uma nova tendência, na qual predomina o imperativo do domínio de certas estruturas e da colocação em circulação de artigos que, por sua aparência, estariam cumprindo a função de divulgar conhecimento. Legitimar tal modelo, tendo em vista o padrão de texto acadêmico veiculado hoje em revistas científicas e em outros veículos destinados à sua circulação, exige cautela. Sabe-se que, atualmente, a produção acadêmica e científica tem sua qualidade questionada, inclusive por trabalhos que se dedicam a estudar as citações nela presentes. Indagações sobre sua originalidade, confiabilidade e utilidade são cada vez mais corriqueiras, seja dentro ou fora da academia. Assim, premiar com notas altas redações que se assemelham a essa produção parece algo pernicioso. Comunica-se aos candidatos aprovados e, indiretamente, à sociedade em geral que a mimese de textos acadêmicos e científicos é benigna, e o resultado pode ser a instauração e a perpetuação de um ciclo de penúria intelectual. O candidato deixa de buscar a construção de uma posição própria na redação de vestibular

\footnotetext{
${ }^{4}$ Destaca-se que o primeiro parágrafo, destinado basicamente a sintetizar aspectos da obra de Kant, corresponde a mais da metade da redação.
} 
a fim de se enquadrar em um padrão; quando universitário, poderá tender a repetir o processo em seus trabalhos escolares; quando pesquisador, é possível que se cale diante do conhecimento estabelecido e se limite a ecoar aquilo que autores consagrados afirmaram em suas obras; quando professor, poderá ficar restrito à transmissão de seu modus operandi a pupilos... E a ciência, a academia, a sociedade perdem. Contentar-se com o início de uma formação para tal ciclo desde o ensino médio (que tem, entre outras funções, o papel de preparar os alunos para o vestibular e a universidade) é contribuir para perpetuar esse quadro.

Há esperança? Ou melhor, existe meio de interromper o ciclo? Pensa-se que sim. Considera-se necessário um reset no modo de enxergar a redação de vestibular e mesmo o próprio texto acadêmico e científico, pois o que os corretores fazem em seu serviço, premiando redações com máscara de ciência, não seria a reprodução daquilo que muitas vezes ocorre na avaliação de textos acadêmicos e científicos (quando se privilegiam trabalhos repletos de citações mas carentes de autenticidade no lugar de trabalhos repletos de autenticidade mas carentes de citações)? Parece indispensável deslocar o foco do olhar de um padrão ou modelo para a natureza íntima ou essência dos textos, isto é, para o que o autor demonstra de próprio a um sujeito, que articula o que sabe, o que já está em circulação em favor de uma elaboração nova; reposicionar a apreciação de modo que seja mais subjetiva e menos restrita a formas consolidadas. 


\begin{tabular}{|c|c|}
\hline 1999 & $\begin{array}{l}1^{\circ}-\text { Joaquim Maria Machado de Assis e Luis Vaz de Camões (2 redações) } \\
2^{\circ} \text { - Fundação Universitária para o Vestibular, Karl Marx, Rita Lee, Thomas } \\
\text { Hobbes, Charles Darwin, Daniel Goleman, Caetano Veloso, Gilberto Gil, } \\
\text { Gilberto Dimenstein, Jacques Marcovith, Oscar Wilde (1 redação) }\end{array}$ \\
\hline 2000 & $\begin{array}{l}1^{\circ} \text { - Oswald de Andrade (6 redações) } \\
2^{\circ} \text { - Mário de Andrade ( } 5 \text { redaçס̋es) } \\
3^{\circ} \text { - Gilberto Freyre e Caetano Veloso ( } 3 \text { redaçōes) } \\
4^{\circ} \text { - Olavo Bilac, João Guimarães Rosa, Aurélio Buarque de Holanda } \\
\text { Ferreira e Brasil ( } 2 \text { redações) } \\
5^{\circ} \text { - Fred Zero Quatro, Chico Science, Hannah Arendt, Raymond Aron, José } \\
\text { Saramago, Eduardo Prado, Ivan Pavlov, Fernando Pessoa, Luís Vaz de } \\
\text { Camóes, Karl Marx, Rodrigo Naves, Jean-Baptiste Debret, Graciliano } \\
\text { Ramos, William Shakespeare, Benedito Rui Barbosa, Chico Buarque de } \\
\text { Holanda, John Lennon, Nicolau Maquiavel, Benito Mussolini (1 redaçăo) }\end{array}$ \\
\hline 2001 & $\begin{array}{l}1^{\circ} \text { - Karl Marx ( } 3 \text { redações) } \\
2^{\circ}-\text { Thomas Malthus, Heródoto, Jean-Jacques Rousseau, José Saramago, } \\
\text { Theodor Adorno, Gilberto Freyre, Friedrich Nietzche, Gonzaguinha, Joaquim } \\
\text { Maria Machado de Assis, Mário de Andrade, José de Alencar, Cazuza, } \\
\text { Jean-Paul Sartre, George Duby, Anthony Giddens, Fernando Pessoa [Álvaro } \\
\text { de Campos], Domenico de Masi, Platão, Charles Darwin, Albert Einstein, } \\
\text { João Guimarães Rosa, Santo Agostinho, S. E. Castan, Krzysztof Kieslowski, } \\
\text { Hannah Arendt (1 redação) }\end{array}$ \\
\hline 2002 & $\begin{array}{l}1^{\circ} \text { - Paulo Freire, Jean-Paul Sartre, Jean Piaget, Fernando Henrique } \\
\text { Cardoso, Renato Russo, João Guimarães Rosa (2 redações) } \\
2^{\circ}-\text { Graciliano Ramos, Zé Ramalho, Jean-Jacques Rousseau, Eric } \\
\text { Hobsbawn, Geraldo Vandré, Victor Hugo, Elis Regina, Immanuel Kant, } \\
\text { Sigmund Freud, Susanna Tamaro, Michael Faraday, Georg Hegel, Charles } \\
\text { Darwin, Herbert Spencer, Jeremy Bentham, Carlos Drummond de Andrade, } \\
\text { Eduardo Suplicy, Aldous Huxley, Gill Vicente, Nicolau Maquiavel, Platão, } \\
\text { Manuel Bandeira, Walter Elias Disney, Isaac Newton, Carl Jung, Paulo } \\
\text { Renato [Ministro da Educação], Denis Diderot, Jürgen Habermas, Louis } \\
\text { Althusser, Thomas Hobbes, Joaquim Maria Machado de Assis (1 redação) }\end{array}$ \\
\hline 2003 & 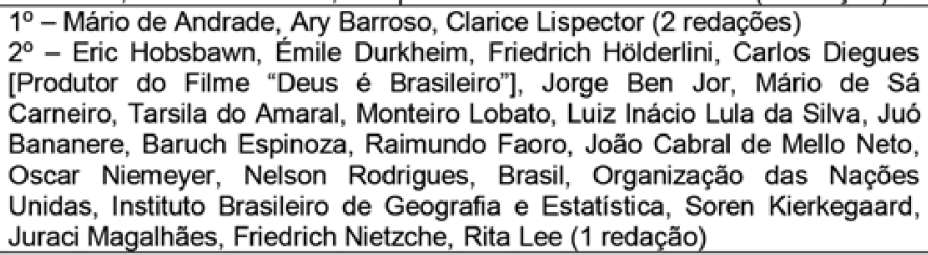 \\
\hline 2004 & $\begin{array}{l}1^{\circ} \text { - Karl Marx (3 redações) } \\
2^{\circ} \text { - Santo Agostinho e Georg Hegel (2 redações) } \\
3^{\circ} \text { - Pedro Américo, Charles Darwin, Organização das Naçäes Unidas, } \\
\text { Norbert Elias, Joaquim Maria Machado de Assis, Max Weber, Immanuel } \\
\text { Kant, Albert Einstein, Jean-Pauul Sartre, Vinicius de Moraes, Antonio Palloci, } \\
\text { Paulinho da Viola, Clarice Lispector, Jean Chesneaux, George Orwell, } \\
\text { Fernando Pessoa [Álvaro de Campos], Max Horkheimer, Theodor Adorno, } \\
\text { Salvador Dali, Charles Chaplin, Lulu Santos, Tony Garrido (1 redação) }\end{array}$ \\
\hline
\end{tabular}




\begin{tabular}{|c|c|}
\hline 2005 & $\begin{array}{l}1^{\circ}-\text { Sigmund Freud ( } 2 \text { redações) } \\
2^{\circ}-\text { Thomas Hobbes, Caetano Veloso, Marcel Duchamp, Roland Barthes, } \\
\text { Michel Foucault, Zé Ramalho, Charles Darwin, Simon Bolivar, Frederico } \\
\text { Fellini, Oswald de Andrade, Clarice Lispector (1 redaçäo) }\end{array}$ \\
\hline 2006 & $\begin{array}{l}\text { Georg Hegel, Karl Marx, Max Weber, Joseph Mankiewicz, Tennessee } \\
\text { Williams, Peter Drucker, Ricardo Antunes, Aristóteles, Jean de La Fontaine, } \\
\text { Michel Foucault, Sigmund Freud ( } 1 \text { redaçấo) }\end{array}$ \\
\hline 2007 & $\begin{array}{l}1^{\circ}-\text { Aristóteles ( } 3 \text { redações) } \\
2^{\circ}-\text { Vinicius de Moraes e Thomas Hobbes (2 redações) } \\
3^{\circ}-\text { Tom Jobim, Voltaire, Sócrates, Platão, Karl Marx, Friedrich Engels, } \\
\text { Roger Bastide, Pierre Verger, Odin [Hávamál], Friedrich Nietchze, José de } \\
\text { Alencar, Xue Xinran, José Maria de Eça de Queirós, Immanuel Kant, } \\
\text { Moisés, Padre Antônio Vieira, Paulo Leminski, Jean-Paul Sartre, Arthur } \\
\text { Schopenhauer, Cecília Meireles, Sêneca, Fernando Pessoa, Cícero, Émile } \\
\text { Durkheim, Adam Smith, Joaquim Maria Machado de Assis, Samuel, Google } \\
\text { [Orkut], Barão Vermelho, Zygmunt Bauman, Robert Zemeckis [Diretor do } \\
\text { Filme "O Naufrágo"], Jean-Jacques Rousseau, Milton Santos, Miguel de } \\
\text { Cervantes, Raquel de Queiróz, Michel de Montaigne (1 redação) }\end{array}$ \\
\hline 2008 & $\begin{array}{l}1^{0} \text { - José Maria de Eça de Queirós, Carlos Drummond de Andrade, } \\
\text { Wikipédia (2 redações) } \\
2^{\circ} \text {-Veja [Revista], Marilena Chaui, Edmund Husserl, Fiódor Dostoiévski, } \\
\text { Joaquim Maria Machado de Assis, Stephen Kanitz, Fernando Anitelli, } \\
\text { William-Adolph Bouguereau, Michael Hart [Project Gutenberg], Fundação de } \\
\text { Amparo à Pesquisa do Estado de São Paulo [Scientific Electronic Library } \\
\text { Online], Google, Yahoo!, Newsweek, Friedrich Nietzche, Giovanni Sartori, } \\
\text { Organização das Naçőes Unidas, Janet Murray, Sócrates, Jacques Le Gooff, } \\
\text { Milton Santos, Zygmunt Bauman (1 redação) }\end{array}$ \\
\hline 2009 & $\begin{array}{l}1^{\circ}-\text { Albert Einstein ( } 3 \text { redações) } \\
2^{\circ}-\text { Isaac Newton, Galileu Galilei, Graciliano Ramos, Carlos Drummond de } \\
\text { Andrade, Joăo Guimarăes Rosa, Michel Foucault, Ludwig van Beethoven, } \\
\text { John Lennon ( } 2 \text { redaçőes) } \\
3^{\circ}-\text { Organização das Nações Unidas, Luis Vaz de Camões, Zygmunt } \\
\text { Bauman, Luiz Felipe de Alencastro, Paulo [Carta de Paulo a Efésios], } \\
\text { Friedrich Schiller, Martin Luther King, Charles Darwin, Gregor Mendel, } \\
\text { Nicolau Copérnico, Sigmund Freud, Milton Santos, Gilles Deleuze, Salomão, } \\
\text { Pierre-Joseph Proudhon, Joaquim Maria Machado de Assis, Immanuel Kant, } \\
\text { Jacques Lacan, Karl Marx, Arthur Schopenhauer (1 redação) }\end{array}$ \\
\hline 2010 & 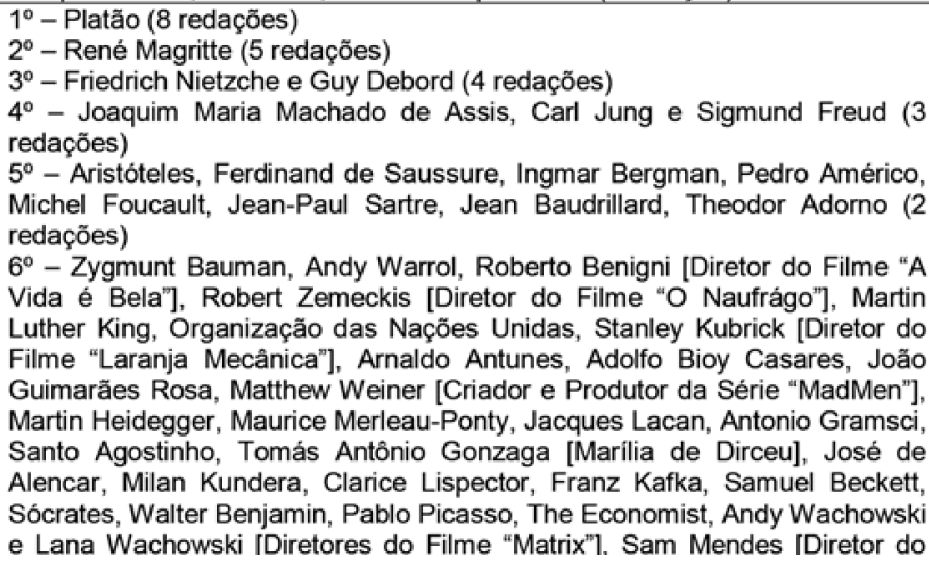 \\
\hline
\end{tabular}

SignUM: Estud. Ling., Londrina, n. 18/2, p. 121-148, dez. 2015 
Filme "Beleza America"], Jorge Amado, Gil Vícente, Graciliano Ramos, Miguel de Cervantes, Linden Lab [Jogo "Second Life"], Jacques Derrida, Luiz

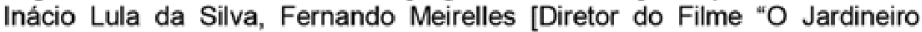
Fiel"], Fernando Pessoa, Arthur Schopenhauer, Joseph Goebbels, Steven Soderbergh [Diretor do Filme "Che"], Michael Moore, Émile Durkheim, Claude Lévi-Strauss, Joseph Campbell, Simone de Beauvoir, Oscar Wilde, Maurits Cornelis Escher, Robbin Willians, Thomas Hobbes, Mino Carta, Gilles Lipovetsky (1 redação)

$1^{0}-$ Zygmunt Bauman (6 redaçöes)

$2^{\circ}$ - Karl Marx (5 redações)

$3^{\circ}$ - Aristóteles (4 redações)

$4^{\circ}$ - Clinton Richard Dawkins, José Maria de Eça de Queirós, Renato Russo, Hanna Arendt, Joaquim Maria Machado de Assis, Thomas Hobbes (2 redaçōes cada)

$2011 \quad 5^{\circ}$ - Jean-Paul Sartre, Dante Alighieri, Nicolau Sevcenko, Alfredo Bosi, Raul Seixas, Gabriele Muccino [Diretora do Filme "Sete Vidas"], Chico Xavier, Aluísio de Azevedo, Jean-Pierre Jeunet, José Saramago, Georg Hegel, John Maynard Keynes, Sérgio Buarque de Holanda, Friedrich Nietzche, Lewis Carrol, George Orwell, Friedrich Engels, Eric Hobsbawn, Emile Durkheim, Slavoj Zizec, Marshall Berman, Charles Darwin, David Fincher [Diretor do Filme "Rede Social"], Nicolau Maquiavel, William Shakespeare, Avaaz, Milton Santos, Adam Smith (1 redação)

\begin{tabular}{|c|c|}
\hline 2012 & 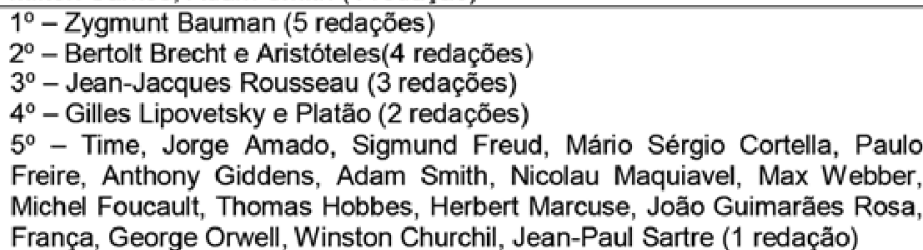 \\
\hline 2013 & 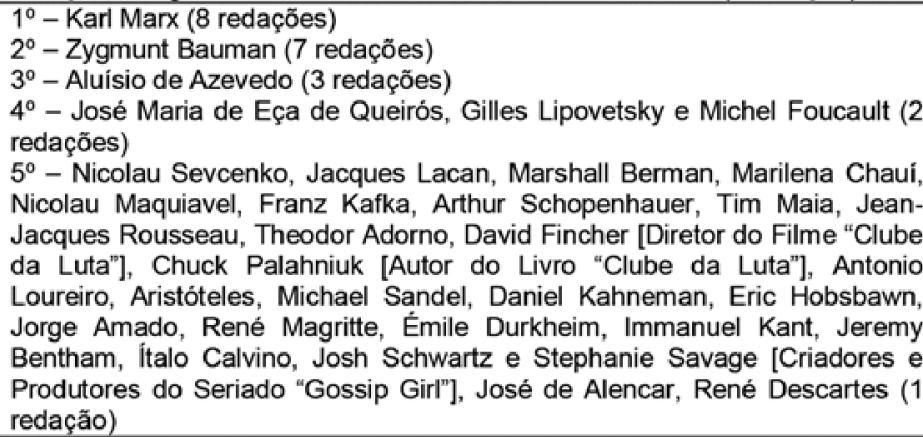 \\
\hline
\end{tabular}

Figura A - Relação completa dos autores de fontes externas citados no corpus e sua frequência. 


\section{Referências}

AMERICAN PSYCHOLOGICAL ASSOCIATION. Publication manual of the American Psychological Association. 6th ed. Washington: American Psychological Association, 2009.

ASSOCIAÇÃO BRASILEIRA DE NORMAS TÉCNICAS - ABNT. NBR 10520: Informação e documentação - Citações em documentos Apresentação. Rio de Janeiro: ABNT, 2002. 7p.

BARZOTTO, V. H. Leitura e produção de textos: limites e relações intersubjetivas. In: CALIL, E. (Org.). Trilhas da escrita-autoria, leitura e ensino. São Paulo: Cortez, 2007. p. 159-170.

BISCIONE, F. M. et al. Avaliação de efetividade da atenção domiciliar de uma cooperativa médica de Belo Horizonte, Minas Gerais, Brasil. Cadernos de Saúde Pública, Rio de Janeiro, v. 29, supl. 1, p. s73-s80, 2013.

BORBA, M. L. de; HOELTGEBAUM, M.; SILVEIRA, A. A produção científica em empreendedorismo: análise do Academy of Management Meeting: 1954-2005. Revista Administração Mackenżie, São Paulo, v. 12, n. 2, p. 169-206, mar./abr. 2011.

CASTALDO, M. M. Redação no vestibular: a língua cindida. 2009. Tese (Doutorado em Educação) - Universidade de São Paulo, São Paulo.

CATELLAN, J. C.; BOTTEGA, R. M. D. O texto como agenciamento autoral de vozes: a redação no vestibular. Letras \& Letras, Uberlândia, v. 19, n. 2, p. 41-56, jul./dez. 2003.

FUNDAÇÃO UNIVERSITÁRIA PARA O VESTIBULAR - FUVEST. Algumas das melhores redações [Vestibulares 1999-2013]. Disponível em: $<$ http://bit.do/bFaqF>. Acesso em: 15 ago. 2013. [Material coletado entre junho e agosto de 2013].

HAMADA, M.; HIRAO, T.; YUI, K. Daigakusei to ryîgakusei no tame no ronbun wâkubukku. Tokyô: Kurosio, 1997. 
LUSTOSA, L. A. et al. Citation distribution profile in Brazilian journals of general medicine. Sao Paulo Medical Journal, São Paulo, v. 130, n. 5, p. 314-317, 2012.

MARCONI, M. de A.; LAKATOS, E. M. Fundamentos de metodologia cientifica. 6. ed. São Paulo: Atlas, 2005.

MARQUES, J. G. A redação no vestibular: O uso da coletânea e a intertextualidade. 1997. Dissertação (Mestrado em Linguística Aplicada) Universidade Estadual de Campinas, Campinas.

ROCCO, M. T. F. Crise na linguagem: a redação no vestibular. São Paulo: Mestre Jou, 1981.

RODRIGUES, A. F. Como elaborar citações e notas de rodapé. 5. ed. São Paulo: Humanitas, 2009.

SAMPAIO, M. I. Citações a periódicos na produção científica de psicologia. Psicologia: Ciência e Profissão, Brasília, v. 28, n. 3, p. 452-465, 2008.

SEVERINO, A. J. Metodologia do trabalho científico. 22. ed. rev. e ampl. (de acordo com a ABNT). São Paulo: Cortez, 2002.

SILVA, M. das G. e; ARAUJO, N. M. S.; SANTOS, J. S. "Consumo consciente": o ecocapitalismo como ideologia. Revista Katálysis, Florianópolis, v. 15, n. 1, p. 95-111, jan./jun. 2012. Disponível em: <http://bit.do/bFarg>. Acesso em 7 out. 2013.

VIEIRA, F. G. D. Narciso sem espelho: a publicação brasileira de marketing. Revista de Administração de Empresas, São Paulo, v. 43, n. 1, p. 81-90, jan./ mar. 2003.

Recebido em: 23/10/2014 Aceito: 02/02/2015 